\title{
Investigation of Mechanism of Tool Electrode Wear in Tube Electrode High-Speed Electrochemical Discharge Drilling
}

\author{
Yan Zhang ${ }^{1, *}$, Jian Tang ${ }^{1}, \mathrm{Yu}$ Wang $^{2}$, Qin $\mathrm{Ni}^{1}$ and Lei $\mathrm{Ji}^{1}$ \\ ${ }^{1}$ School of Mechanical and Power Engineering, Nanjing Tech University, Nanjing 211800, PR China \\ ${ }^{2}$ AECC Sichuan Gas Turbine Research Establishment, Sichuan 610500, PR China \\ *E-mail: zhangyanzy@njtech.edu.cn
}

doi: $10.20964 / 2019.12 .15$

Received: 3 July 2019 / Accepted: 2 September 2019 / Published: 29 October 2019

\begin{abstract}
In tube electrode high-speed electrochemical discharge drilling (TSECDD), owing to electrical discharge erosion, tool electrode wear cannot be avoided and seriously affects the machining accuracy and efficiency of micro holes. To solve this problem, in this study, the mechanism of the tool electrode wear in TSECDD is investigated from three aspects: electrochemical reaming, gas film and sputtering layer. Moreover, a series of studies is conducted to identify the mechanism of the tool electrode wear in TSECDD. First, by comparing the tool electrode wear in electrical discharge machining (EDM) and TSECDD, it is found to be reduced by $14.75 \%$ when using TSECDD. By optimization experiments, it is then concluded that when the working fluid conductivity is $10 \mathrm{mS} / \mathrm{cm}$, pulse width is $15 \mu \mathrm{s}$, pulse interval is $38 \mu \mathrm{s}$, and peak current is $8 \mathrm{~A}$, the tool electrode wear is the least. Finally, the optimized parameters are used for hole machining, which proves that the improved tool electrode wear can effectively improve the machining performance of the hole.
\end{abstract}

Keywords: electrical discharge machining; electrochemical reaction; tool electrode wear; high-speed machining; micro holes

\section{$\underline{\text { FULL TEXT }}$}

(C) 2019 The Authors. Published by ESG (www.electrochemsci.org). This article is an open access article distributed under the terms and conditions of the Creative Commons Attribution license (http://creativecommons.org/licenses/by/4.0/). 